\title{
Using Video Modeling Package on Improving Workplace Social Skills of Young Adults with Talent Traits and Autism: A Case Study
}

\author{
Ching-Chih Kuo ${ }^{1}$, Yen-Chun Tseng ${ }^{1}$, Cheng-Fen Chang ${ }^{1}$, Chin-Shueh Chen ${ }^{1}$, Yu-Jin Li ${ }^{2}$, \\ Hui-Ting Wang ${ }^{1, *}$ \\ ${ }^{1}$ Department of Special Education, National Taiwan Normal University, Taiwan \\ ${ }^{2}$ Song Shan High School of Commerce and Home Economics, Taiwan
}

Received October 17, 2019; Revised November 20, 2019; Accepted November 26, 2019

Copyright $\bigcirc 2019$ by authors, all rights reserved. Authors agree that this article remains permanently open access under the terms of the Creative Commons Attribution License 4.0 International License

\begin{abstract}
Stable, positive relationships with colleagues or supervisors are difficult for students with autism spectrum disorder (ASD) to maintain. Little was known in teaching social skills of students with ASD in workplace, not mentioning for those who have ASD as well as talent traits. This pilot case study aimed to use a package of cognitive behavioral training, applied behavior analysis (ABA) guidelines, and secondary-tier generic video modeling to teach workplace social skills to five young adults with ASD and talent traits. The intervention lasted for 8 weeks, with 3 hours of intervention each week. Per ABA guidelines, the authors focused on the talent traits and preferred activities of the participants with ASD, and structured the training to include a reward system and opportunities to practice learned skills in the community. Analysis using nonparametric statistics revealed a significant difference between the means of pretest and posttest scores $(Z=2.032, p<.05)$ on a curriculum-based assessment. Significant improvements among the participants were noted on their assessments of all five target skills, on the teacher $\log$, and through interviews. This study requires further replication with rigorous design to make causal conclusion.
\end{abstract}

Keywords Autism Spectrum Disorder, Video Modeling, Social Skills, Talent Trait

\section{Introduction}

The core characteristics of autism spectrum disorder (ASD) are challenges in exhibiting reciprocity, emotional responses, and motor behaviors required for interpersonal interaction development [19]. Examples of relevant behaviors include performance of appropriate facial expressions and discernment of people's emotions used for developing, maintaining, and understanding relationships. When individuals with ASD become adults, social interaction deficits continue to affect them and may worsen or cause additional problems. For example, these individuals may face difficulties in developing relationships with colleagues or romantic relationships with people of the opposite sex, and further challenges may arise in maintaining daily lives or employment $[3,21]$. These challenges are major inhibitors to employment success for adults with ASD [18].

Meaningful, integrated employment should be available for all individuals with ASD who are graduating from college and intend to work [33]. Research conducted by Hendricks [17] suggested that the employment outcomes for ASD are disappointing: the rate of unemployment remains high and underemployment is common. Additionally, approximately $50 \%$ to $75 \%$ of adults with ASD in the United States are unemployed [16, 23, 24, 35]. Obtaining and maintaining employment can be difficult for any person, and may be especially complicated for an adolescent with ASD [30, 38, 40. Research findings have indicated that the factors of "more independent daily living skills, a higher family income, a larger maternal social network, an inclusive school environment in early childhood, and currently living in an area with a larger population size" were associated with a higher likelihood of sustained employment among adults with ASD [7] (p.1). Many reports have indicated that although people with mild ASD do not have intellectual disabilities, many cannot maintain jobs and remain unemployed $[21,39]$.

The Individuals with Disabilities Education Act of the United States states that the primary purpose of a public education is to prepare an individual for employment [17]. 
Employment may offer special benefits for individuals with ASD. For instance, employment can enhance their sense of dignity and improve their quality of life $[9,11,42]$ and cognitive performance [10]. From a government's perspective, increased employment among these individuals may also offer economic advantages; employed individuals rely less on government funds and contribute more in taxes [22]. Once employed, individuals with ASD may display particular strengths that help them increase work output and enjoy performing jobs [48]. According to interviews reported in the literature, communication and social difficulties with supervisors and coworkers are the primary hindrance to positive job performance for individuals with ASD $[5,38]$. Therefore, during their final stage of education, adolescents with ASD should receive employment transition training, especially training for developing workplace social skills [23].

Literature of individuals with both ASD and talent traits is scarce. According to Special Education Act in Taiwan [43], "talent" is defined in six areas, general intelligence aptitude, specific academic aptitude, visual and performing arts, creative and productive thinking, leadership ability, and other aptitudes. This population is often seen first for their talent traits; thus, their challenges may be similar to those with only ASD yet needs to develop social skills is more often neglected. This study aims to investigate the effects of group-based video modeling (VM) package for improving workplace social skills among adults with talent traits and ASD in Taiwan and to contribute to the literature as an attention inducing pilot study.

\subsection{Evidence-based Social-skills Training for Adolescents with ASD}

Research on strategies for instructing adolescents or adults with ASD is scarce, and research on teaching skills to this group in the workplace is even more uncommon [17]. Several evidence-based practices (EBP) emerged and were identified by the National Professional Center on ASD [53] based on the Horner classic article on criteria of EBP [20].

Social-skills training is a type of child-specific intervention [36] and is an EBP used for group instruction of people with ASD [53]. This intervention involves teaching specific skills (e.g., maintaining eye contact and initiating conversation) through behavioral and social learning techniques [8]. However, definitions of social skills and behavior outcomes vary according to a child's deficits or the specific social behaviors targeted in an intervention [44]. Merrell and Gimpel [37] argued that social-skills training curricula should be designed like normal subject curricula and should consider the behaviors that participants exhibit upon starting the course. Another EBP for teaching children with ASD of their social skills, cognitive behavioral training, emphasizes on observation and social coding. It has been used for teaching social skills based on a seven-element process: motivation, introduction of skills and steps, performance of steps, situational practice, feedback, reinforcement, and further practice $[6$, 14].

Studies on social skills have comprehensively examined the use of teaching technology in ABA. Related studies have covered social scripts, peer modeling, cooperative learning groups, peer tutoring, class-wide interventions, pivotal skills, incidental teaching, structured reward systems, VM, errorless learning, graduation guidance, and systems of prompts $[17,50]$. The researches of Burt and colleagues [4] and Smith [48] have supported the use of these strategies derived from the principles of ABA.

Given the heterogeneity of people with ASD, a variety of services and support systems must be provided for this population to gain and maintain employment and participate in their communities. Keel et al. [25] emphasized the need for job placement to be based on an individual's strengths and interests. Jobs should be identified according to the individual's intellectual and educational background and should match his or her abilities [22, 34]. Several strategies for identifying appropriate jobs have been mentioned in the literature, including job preference [41], preference assessments [26], and multi-stimuli assessments [27]. These assessments include behavior observations, situational assessments, and analyses of background information. Additionally, on-site job training may be most beneficial, because people with autism exhibit unique learner profiles. In their study, Lattimore et al. [28] paired simulation tasks with on-the-job training and demonstrated that on-site training increased the skill acquisition of adults with autism.

\subsection{Video Modeling of Workplace Social Skills}

An increasing number of researchers have focused on using VM, another EBP, to train people with ASD [53]. A literature review conducted by Wang and Koyama [49] indicated several advantages of using VM to instruct people with ASD: (a) VM provides an antecedent stimulus and primes learners to predict tasks and related processes $[2,45]$; (b) all necessary stimuli and instructions can be included in the same video; (c) videos can replace trained personnel in instructing learners; (d) VM implementation does not require much expertise and simple instructions can be standardized for future replication $[12,46]$. Only a few evidence-based studies that focus on using VM to teach social skills to people with autism have been conducted [e.g., 15, 29, 47]. Thus far, no study has used $\mathrm{VM}$ as the main tool to teach workplace social skills to adults with autism.

Wang and Koyama [49] proposed a three-tier VM intervention model as a framework for re-allocating resources for people with ASD. The three tiers are structured according to three target groups and the corresponding amounts of required resources and support. 
The primary tier involves self-administered generic VM for learners who respond to interventions that require minimal resources and support. The secondary tier comprises group-based instruction for learners who may respond to interventions that require a moderate amount of resources and support. Lastly, the tertiary tier involves individualized $\mathrm{VM}$ for learners who require the maximum amount of resources and support for intervention. The secondary tier VM intervention may be used to facilitate group instruction based on a combination of VM and social- skill group training EBPs.

This study applied secondary tier VM group intervention to improve workplace social skills among students with talent traits and ASD. In the group intervention, we included generic VM videos, Goldstein's seven elements of cognitive behavioral training [13, 14], and ABA guidelines (preference assessment, modeling, structured reward system, and social scripts), as suggested in the literature.

\section{Research Method}

This case study applied a one-group pretest-posttest design and qualitative approach, such as teacher log and interviews.

\subsection{Participants}

The inclusion criterion for recruitment of participants were: (a) aged between 16 to 30 years old; (b) received diagnosis of Aspergers' or autism; (c) received Wechsler Intelligence Scale for Children (WISC) score above 100 and performed above average in one of any domains; (d) talent traits demonstrated in any of the areas defined by the Special Education Act in Taiwan [43] through award at a contest with at least third place or above. Participants were five young adults with mild ASD and talent traits, and their average age was 24 years (Table 1). They either held a fulltime job or a part-time job at the time of the study. One participant withdrew from the study due to a strong desire to avoid interacting with others. All participants had received clinical diagnoses of ASD based on the Diagnostic and Statistical Manual of Mental Disorders
Fifth Edition [1] diagnostic criteria, and these diagnoses had been further confirmed by the Autism Diagnostic Interview-Revised [32]. Their talent traits were recognized primarily by international and national awards. The participants managed their daily lives well, had attended inclusive schools through college, and had maintained positive relationships with their mothers.

Our participants are introduced in Table 1.

Peng graduated from the area of Graphic Arts. He presents his unique style in his painting and his fashion. $\mathrm{He}$ has won several awards, such as the Disabled Pride Prize for Artistic Creation, for which he was recognized by the Office of the President. He also participated in the World Conference on Gifted and Talented Children Exhibition. $\mathrm{He}$ is able to communicate with others easily, even with people that he is meeting for the first time. However, he is also straightforward and not afraid of criticizing others. When he must cooperate with others, he only performs the tasks that he wants to perform.

Sheng majored in visual communication design in college. He has exhibited mild autism and developmental delays since childhood, and because of these challenges he experienced tremendous hardships growing up. Although he struggled to keep up with his peers in academics and other areas of life, he demonstrated a talent for painting, which he taught himself from elementary school to junior high school. He used Chinese ink to paint houses, and he won the premium prize in the National Student Art Exhibition. He also won the National Picture Book Writing Competition. At the beginning of the course in the present study, Sheng was too shy to talk to others because he felt embarrassed. He exhibited difficulties initiating conversation and cooperating with his classmates.

Yuan was identified as a gifted student in school. He held several part-time jobs after he graduated from college, but was unable to choose a career path. He seldom talked to his colleagues at work and had few friends that he could talk to after work. During the interview for the present study, he expressed hope that through the social skills training course he could improve his ability to hold conversations with others.

Table 1. articipant list

\begin{tabular}{|c|c|c|c|c|c|}
\hline ID & Sex & Age & Talent traits & Interests and strengths & Past job experience \\
\hline Peng & M & 25 & $\begin{array}{c}\text { Art, history, } \\
\text { being stylish }\end{array}$ & Art, history & Artist \\
\hline Sheng & M & 22 & Art & $\begin{array}{c}\text { Art, history, } \\
\text { architecture-related topics }\end{array}$ \\
\hline Yuan & M & 27 & $\begin{array}{c}\text { Keen sensory } \\
\text { awareness }\end{array}$ & Making tea & $\begin{array}{c}\text { Engineer in a computer company (full-time) } \\
\text { Server in a tea house (part-time) }\end{array}$ \\
\hline Xuan & F & 24 & Art & Art, food & $\begin{array}{c}\text { Design assistant in an advertising company (part-time) } \\
\text { Artist }\end{array}$ \\
\hline Ting & F & 32 & Art & $\begin{array}{c}\text { Art, history, food, car- and } \\
\text { bus-related topics, and } \\
\text { Egyptian culture }\end{array}$ & $\begin{array}{c}\text { After-school teacher (part-time) } \\
\text { Art gallery curator }\end{array}$ \\
\hline
\end{tabular}


Xuan majored in fine arts and culture creative design. She began treatment with medication in college. She won the International Competition for Writers with Disabilities in 2015 and was recognized in Taiwan's $55^{\text {th }}$ Ten Outstanding Young Persons awards in 2017. At the beginning of the study, she excelled at following others' rules with regard to topics she is not interested in, but when she formulated her own opinion on a matter, she refused to change it. Because of her limited interests, she did not know how to initiate conversations with others. When she went out with her friends, she discussed the same topics repeatedly. After beginning a job at an advertisement company, she encountered difficulties in getting along with her supervisor.

Ting's symptoms were much more severe than those of the other participants. She could only focus on the few things in which she is interested: food, cars, buses, and Egyptian culture. She also struggled to listen to others carefully, and she only replied to the extent that she wanted. Since graduation, she had held several jobs, and she was an after-school teacher at the time this study started.

\subsection{Video Modeling on Workplace Social Skills Group Intervention}

\subsubsection{Curriculum Development}

This study used "The competence indicators of workplace social skills" [51] as the curriculum foundation and selected the topic "Communication and interaction skills in workplaces" based on the needs of the participants determined from interviews, observations, and pretest results. For example, relevant situations included, "my colleague tells me that she was yelled at by the supervisor this morning," and "my colleague is complaining about the job to me after work." Subsequently, lesson plans were written or modified, and VM videos were developed according to "The social skill training course for vocational school students" [52].

The curriculum development was also designed based on participants' talent traits. For example, the simulated situation was a collaborative art project where Peng, Sheng, and Xuan could unleash their art talent but simultaneously work on their workplace social skills, such as cooperation, collaboration and follow the instructions of employer/supervisor. Arranging tea making activity was because Yuan used to work as a tea maker in the tea house. He could remember the prescriptions precisely of various types of teas. Cultural tour was arranged because Sheng once served as a cultural tour guide.

\subsubsection{Generic VM Videos}

The videos were developed based on models of participants of similar ages, styles of social reinforcement (praise from manager or colleague), task analysis, and narration reported in the literature [49]. The videos consisted of an inappropriate scenario followed by a demonstration of four easy-to- memorize and universal steps: "stop," "calm down," "think," and "act." The scenario was then replayed and possible solutions based on the four steps were presented. These sessions were conducted primarily by the corresponding author and a teaching assistant who was responsible for coordinating scheduling and location, preparing materials, demonstrating skills, and leading discussions. The topic arrangement for the sessions is presented in Table 2 .

Table 2. Social-skills training course summary

\begin{tabular}{|c|c|c|c|}
\hline $\begin{array}{c}\text { Clas } \\
\mathrm{s}\end{array}$ & Topic & Activity for generalization & Design accordance \\
\hline 1 & Pretest & & \\
\hline 2 & Self-introduction & & \\
\hline 3 & Listening to others & $\begin{array}{l}\text { competition for making sticky } \\
\text { rice dumplings }\end{array}$ & $\begin{array}{l}\text { Requires introduction of self and dumplings and listening to others; } \\
\text { talent and interest incorporated }\end{array}$ \\
\hline 4 & Listening to others & $\begin{array}{l}\text { Tour historical district (I) } \\
\text { Afternoon tea }\end{array}$ & $\begin{array}{l}\text { Real-world setting where people are talking; requires listening to } \\
\text { others; talent and interest incorporated }\end{array}$ \\
\hline 5 & $\begin{array}{c}\text { Self-introduction } \\
\text { and listening to } \\
\text { others }\end{array}$ & Tour historical district (II) & $\begin{array}{l}\text { Real-world setting that requires introduction of a topic and listening to } \\
\text { others; talent interest incorporated }\end{array}$ \\
\hline 6 & Initiate conversation & Make tea & Talent traits and interest incorporated \\
\hline 7 & $\begin{array}{c}\text { Maintain } \\
\text { conversation }\end{array}$ & Introduce personal interests & Talent traits and interest incorporated \\
\hline 8 & Posttest & & \\
\hline
\end{tabular}




\subsubsection{Goldstein's Cognitive Behavioral Training Steps [13,} 14]

Class sessions consisted of in-class and outdoor real-world sessions. The primary lecture occurred during class and generalization was practiced in the community.

During every in-class session, the seven elements of instruction were performed as follows: (1) eliciting motivation by integrating a preferred activity, the structured reward system, and the video scenario; (2) introducing or reviewing the universal four steps - "stop," "calm," "think," and "act"—using memory strategies such as simple gestures and rhymes, and repeating the VM segment; (3) modeling the target social skill through application of the four steps; (4) pairing participants to engage in discussion and role-play practice, for which they drew prompts for situations from a box and performed the situations in front of the group; (5) providing feedback and replaying the scenario with possible solutions; (6) providing individualized and specific praise and calculating correct responses for rewards; and (7) distributing a take-home practice task sheet to be completed and signed by a witness for verification. Task sheet completion of the task was considered when calculating the participant's reward in the next class. The reward system will be described in the next section.

\subsubsection{ABA Guidelines}

This study followed ABA guidelines. We designed the activities based on preference assessments. For the preference assessments, we analyzed the participants' background information, especially their talent traits, interests, and strengths; observed their activity choices; and analyzed their results from the simulated workplace task performance pretest. Researchers provided opportunities for participants to demonstrate their special talent traits to enhance the participants' performance in learning social skills in the classes. For example, holding an art exhibition and touring a historical district provided opportunities for the participants to practice what they had learned about listening and initiating conversations. These activities allowed participants to display their talents and helped them apply the skills they had learned to real-world situations.

A structured reward system was utilized to motivate the participants. Each target skill listed on the activity sheets as well as the take-home practice task sheets represented a specific score, and the participants received edible rewards in the real- world settings according to their accumulated score at the end of the class session. The quantity and complexity of the rewards correlated with the scores. For example, when practicing initiating and maintaining conversation, we took the participants to a tea shop where people usually engage in conversations, and participants were offered self-selected choices of snacks of different prices according to their scores.
In addition to use of the preference assessment and structured reward system, the instructor frequently modeled target skills. The instructor initially used social scripts and prompting strategies to guide participants' responses, but these supports were gradually phased out.

\subsection{Pre- and Post-test Measurements}

\subsubsection{Interview}

The interview content focused on the situational tasks. For example, participants were asked about whether they had cooperated with others, whether they had followed the rules set by the first author, and whether they thought they could have improved during the simulated situational task.

\subsubsection{Workplace Social Skills Curriculum-based Assessment Scale and the Simulated Situation}

A simulated workplace task was conducted in pre- and post-test. Participants were asked to hold an exhibition as a team and divide the work among themselves. During the task, the first author created situations to elicit participants' responses, and observed participants' performances under stress, participants' resilience, and the degree to which the participants followed instructions. Their actions in these situations were recorded. Based on the videos, each participant's baseline behaviors were assessed according to the Workplace Social Skills Course- Based Instrument. This measurement is a self-compiled achievement assessment, which was developed based on the teaching objectives of every unit and related course content, and according to curriculum-based assessments to measure the social skills of the five participants. The researchers referred to the self-determination and employment transition service teaching plan instrument-subscale [31] to design self-understanding and unit objectives items for the measurement tool. The first part of the measurement is self-understanding, which comprises five items and was used in this study to evaluate participants' self-concept, cognition, and awareness of workplaces. The second part of the measurement covers unit objectives, which comprise 16 items. A 5-point Likert scale was used for scoring $(1=$ always unable, $2=$ rarely able, $3=$ sometimes able, $4=$ often able, 5 = always able).

The pre- and post-test video recordings were coded by a doctoral student who was naive to the conditions of the study and was asked to rate each test item as objectively as possible based on observation.

\subsubsection{Teaching Log}

The teaching log was self-compiled by the researchers and included teaching records and reflections. Teaching records comprised records of course content, the participants' interactions, and special incidents. Teacher reflections focused on the adjustment of curriculum and the improvement of participants' skills. Suggestions for the next class were also included. 


\subsection{Procedures}

The National Taiwan University Research Ethics Committee approved this study before implementation (Approval No.: 201406EM029). Participants were informed of the purpose and procedures of the study and filled out documents indicating informed consent. Researchers interviewed participants' parents for further information regarding participants' social skills, the problems they encountered most often, and the social skills they most required. Researchers then used the information to develop teaching objectives for the social skills training course.

Two college students majoring in special education participated in the study and acted as peers. They were asked to be energetic and proactive in classes to encourage and inspire the study participants. At the beginning of the course, researchers conducted a simulated workplace task performance as a pretest. Each participant's baseline behaviors were collected using the Workplace Social Skills Course-Based Instrument. The composite score determined from the Workplace Social Skills Curriculum-Based Instrument was used as an indicator of participants' social skills. This measurement process was repeated after the study as a posttest. The course lasted for 8 weeks, and sessions took place once a week from 2 p.m. to 5 p.m. A course summary is illustrated in Table 2.

\subsection{Statistical Analyses}

Curriculum-based measurement (CBM) and nonparametric statistics were used for analysis. CBM involves three steps: establish teaching objectives; conduct CBM; and evaluate improvement according to the results. In addition, the Wilcoxon signed-rank test was used to assess the difference between pretest and posttest scores from the Workplace Social Skills CBM. The Wilcoxon was used because the samples were not normally distributed.

\section{Results}

The results of the Wilcoxon signed-rank test revealed a significant difference between the means of pretest and posttest scores $(Z=2.032, p<.05)$. The mean scores for every item of the posttest were higher than those for the pretest (Figure 1), and the mean scores on the posttest $(M=$ 4.56, $S D=0.23)$ were higher than those on the pretest $(M=$ 3.53, $S D=0.7$; Figure 2).

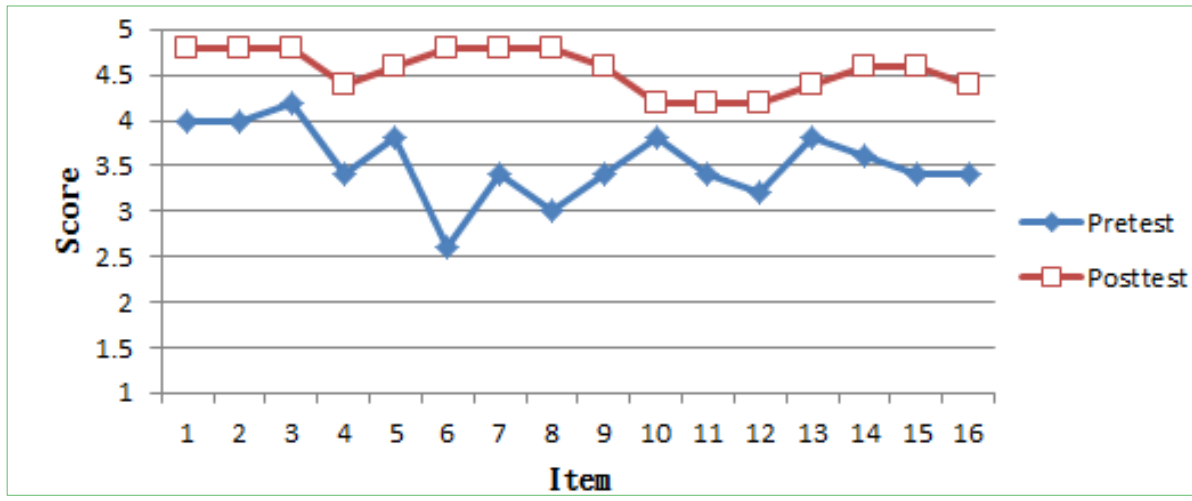

Figure 1. Mean scores for 16 items

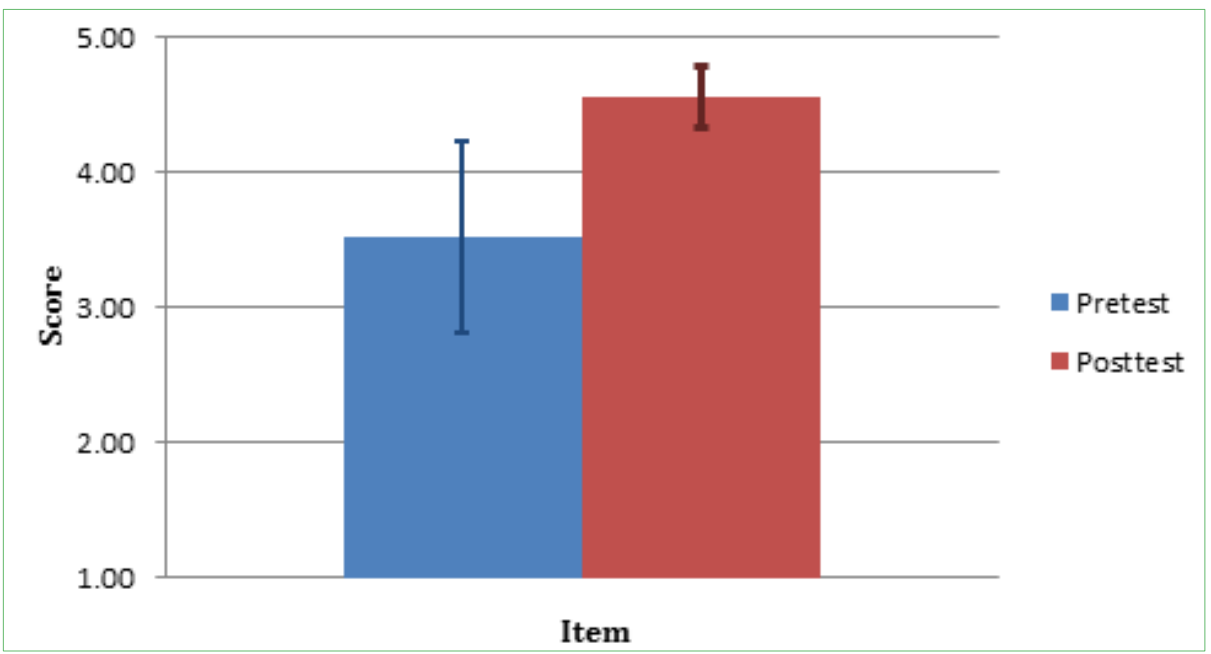

Figure 2. Mean pretest and posttest scores 
Table 3. Descriptive statistics of pretest and posttest results

\begin{tabular}{|c|c|c|c|c|}
\hline \multirow{2}{*}{ Item } & Pretest & Posttest & \multirow{2}{*}{$Z$} & \multirow{2}{*}{$p$} \\
\hline & $M(S D)$ [range] & $M(S D)$ [range] & & \\
\hline $\begin{array}{l}\text { 1. Follow instructions: able to attempt to finish tasks } \\
\text { spontaneously assigned by supervisors. }\end{array}$ & $4.0(.71)[3-5]$ & $4.8(.45)[4-5]$ & 2.00 & $.046^{*}$ \\
\hline $\begin{array}{l}\text { 2. Follow instructions: able to finish tasks assigned by } \\
\text { supervisors in workplaces. }\end{array}$ & $4.0(.71)[3-5]$ & $4.8(.45)[4-5]$ & 2.00 & $.046^{*}$ \\
\hline $\begin{array}{l}\text { 3. Cooperate with others: able to cooperate with others in } \\
\text { workplaces and finish tasks. }\end{array}$ & $4.2(.84)[3-5]$ & $4.8(.45)[4-5]$ & 1.73 & .083 \\
\hline $\begin{array}{l}\text { 4. Cooperate with others: able to communicate with others whose } \\
\text { opinions differ from their own. }\end{array}$ & $3.4(1.14)[2-5]$ & $4.4(.90)[3-5]$ & 1.89 & .059 \\
\hline 5. Cooperate with others: able to invite partners to work together. & $4.2(.84)[3-5]$ & $4.6(.90)[3-5]$ & 1.63 & .102 \\
\hline $\begin{array}{l}\text { 6. Introduce self: able to use appropriate behaviors to introduce } \\
\text { self to others in front of other people. }\end{array}$ & $2.6(.55)[2-3]$ & $4.8(.45)[4-5]$ & 2.12 & $.034 *$ \\
\hline $\begin{array}{l}\text { 7. Introduce self: able to use appropriate language to introduce } \\
\text { self in front of additional people. }\end{array}$ & $3.4(1.14)[2-5]$ & $4.8(.45)[4-5]$ & 1.89 & .059 \\
\hline $\begin{array}{l}\text { 8. Introduce self (generalization): able to use appropriate } \\
\text { behavior to introduce objects or topics to others in front of } \\
\text { additional people. }\end{array}$ & $3.0(1.22)[2-5]$ & $4.8(.45)[4-5]$ & 1.89 & .059 \\
\hline $\begin{array}{l}\text { 9. Introduce self (generalization): able to use appropriate } \\
\text { language to introduce objects or topics to others in front of } \\
\text { additional people. }\end{array}$ & $3.4(.90)[2-4]$ & $4.6(.90)[3-5]$ & 2.12 & $.034 *$ \\
\hline $\begin{array}{l}\text { 10. Listen to others: able to listen patiently and behave } \\
\text { appropriately regardless of discussion topic. }\end{array}$ & $3.8(1.10)[2-5]$ & $4.2(.84)[3-5]$ & 1.63 & .102 \\
\hline $\begin{array}{l}\text { 11. Listen to others: able to concentrate on listening to others } \\
\text { regardless of discussion topic. }\end{array}$ & $3.4(1.52)[3-5]$ & $4.2(.84)[3-5]$ & 1.41 & .157 \\
\hline $\begin{array}{l}\text { 12. Listen to others: able to ask questions related to the } \\
\text { conversations regardless of topic. }\end{array}$ & $3.2(1.64)[2-5]$ & $4.2(.84)[3-5]$ & 1.63 & .102 \\
\hline $\begin{array}{l}\text { 13. Initiate conversations: able to initiate conversation and chat } \\
\text { with others regardless of level of familiarity with the person. }\end{array}$ & $3.8(1.10)[3-5]$ & $4.4(.90)[3-5]$ & 1.34 & .180 \\
\hline $\begin{array}{l}\text { 14. Initiate conversations: able to respond to others after } \\
\text { initiating conversations. }\end{array}$ & $3.6(1.34)[2-5]$ & $4.4(.90)[3-5]$ & 1.63 & .102 \\
\hline $\begin{array}{l}\text { 15. Maintain conversations: able to exchange opinions based on } \\
\text { situations and conversation contents regardless of topics. }\end{array}$ & $3.4(1.14)[2-5]$ & $4.6(.90)[3-5]$ & 1.86 & .063 \\
\hline $\begin{array}{l}\text { 16. Maintain conversation: able to answer questions based on } \\
\text { situations and conversational partners' emotions }\end{array}$ & $3.4(1.14)[2-5]$ & $4.4(1.34)[2-5]$ & 1.63 & .102 \\
\hline
\end{tabular}

$* p<.05, * * p<0.1$

Table 3 depicts descriptive statistics for the 16 items of the measurement. Participants exhibited low scores in the pretest on "6. Introduce self: able to use appropriate behaviors to introduce self to others in front of additional people" $(M=2.6, S D=.55)$, and "8. Introduce self (generalization): able to use appropriate behaviors to introduce objects or topics to others in front of additional people" $(M=3, S D=1.22)$. Participants scored higher in the pretest on "1. Follow order orders: able to attempt to finish tasks that are spontaneously assigned by supervisors" $(M=4, S D=.71)$, "2. Follow orders: able to finish work assigned by supervisors in workplaces" $(M=4, S D=.71)$, and "3. Cooperation with others: able to cooperate with others in workplaces and finish asks" $(M=4.2, S D=.84)$.

The results of the Wilcoxon signed-rank test for each item indicated that participants' mean posttest scores for four items' were significantly higher than the corresponding pretest scores: "1. Follow orders: able to attempt to finish tasks that are spontaneously assigned by supervisors" $(Z=2, p=.046)$; "2. Follow orders: able to finish work assigned by supervisors in workplaces." $(Z=2$, $p=.046) ;$ " 6 . Introduce self: able to use appropriate behaviors to introduce self to others in front of additional people" $(Z=2.12, p=.034)$; and "9. Introduce self (generalization): able to use appropriate language to introduce objects or topics to others in front of additional people" $(Z=2.12, p=.034)$.

Figures 3 and 4 present line graphs of the five participants' scores from the pretest and posttest. Peng (M [pretest $]=4.06, \mathrm{M}$ [posttest $]=5)$ and Sheng $(\mathrm{M}$ [pretest $]=$ 4.69, $\mathrm{M}$ [posttest $=5$ )] scored higher than the others. Table 4 lists the percentage of improvement between pretest and posttest ([mean of posttest-mean of pretest] /mean of pretest $\times 100 \%$ ). Yuan's percentage of improvement was the highest (48.1\%), followed by that of Xuan (44.2\%) and Ting (39.5\%). Peng and Sheng may have earned lower percentages of improvement because their initial scores were relatively high. 


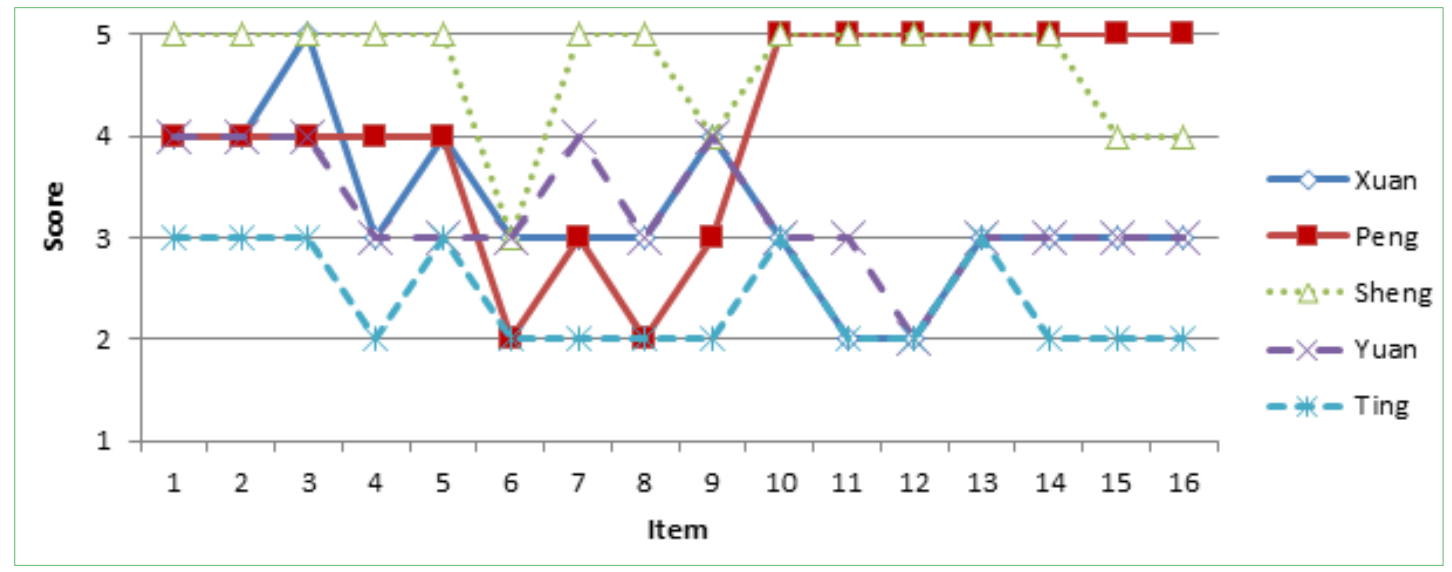

Figure 3. Mean pretest scores of the five participants

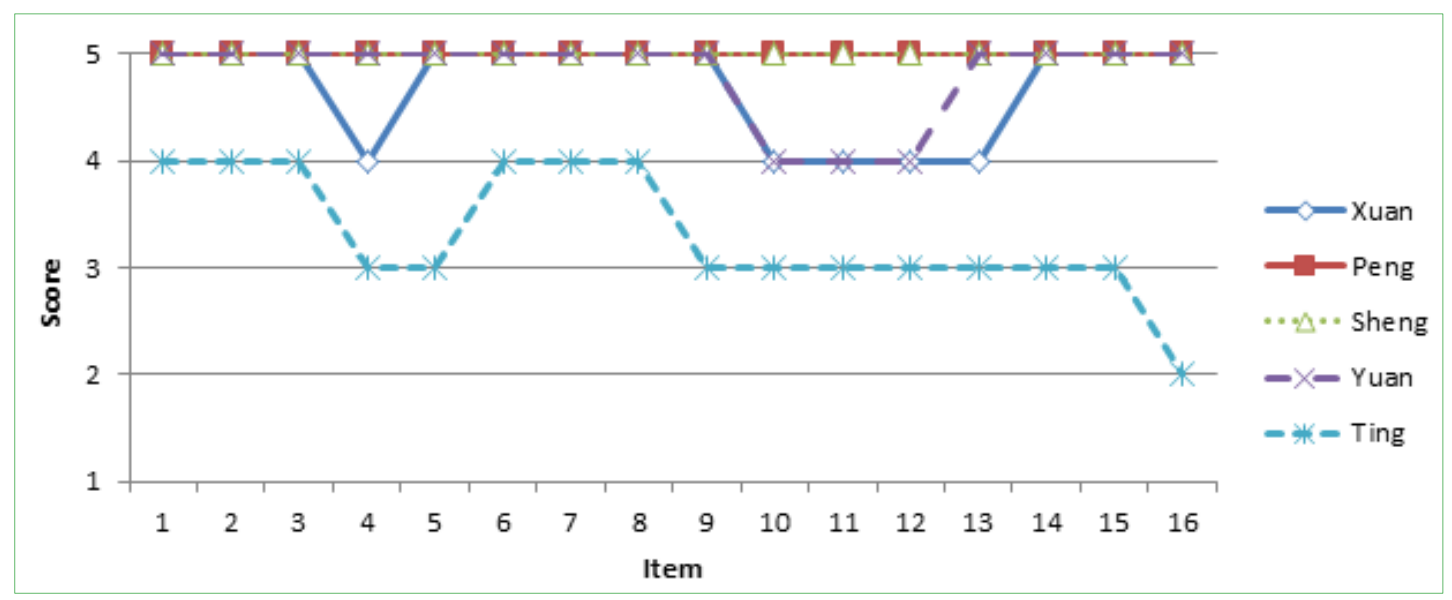

Figure 4. Mean posttest scores of the five participants

Table 4. Score improvement between pretest and posttest

\begin{tabular}{|c|c|c|c|}
\hline & Mean pretest score & Mean posttest score & $\begin{array}{c}\text { Percentage of improvement (Mean of posttest-Mean of pretest)/Mean } \\
\text { of pretest x } 100 \%\end{array}$ \\
\hline Xuan & 3.25 & 4.69 & $44.2 \%$ \\
\hline Peng & 4.06 & 5.00 & $23.1 \%$ \\
\hline Sheng & 4.69 & 5.00 & $6.7 \%$ \\
\hline Yuan & 3.25 & 4.81 & $48.1 \%$ \\
\hline Ting & 2.38 & 3.31 & $39.5 \%$ \\
\hline
\end{tabular}

\section{Discussions and Implications}

This study examined the use of VM to improve the social skills of adults with ASD and talent traits. Social skills are an essential element of successful employment. As mentioned, few studies have focused on using VM as a main tool to teach workplace social skills to adults with ASD and talent traits. Through VM training, individuals can be familiarized with and learn to predict scenarios [49]. VM training can also help individuals identify possible solutions for various situations.

According to the three-tier VM intervention model suggested by Wang and Koyama [49], participants who require universal support and additional assistance are categorized in the secondary tier. By discussing video content with peers, participants with ASD can generate more ideas than they can when listening to a teacher in a lecture session. Furthermore, VM is easy to implement and consistency can be maintained from study to study. Thus, VM can be combined with talent development not only to meet individuals' needs and help them generalize lessons to situations in their daily lives, but also to increase their motivation and improve their social skills.

According to Figures 1 to 4 , the overall study results reflect improvement for all participants in all the items of the curriculum-based assessment. In sum, for this group of individuals with talent traits and ASD, the secondary tier group modeling approach integrated with ABA guidelines 
and cognitive behavioral training enhanced their workplace social skills. The results depicted in Table 3 indicate that the items on which participants significantly improved were within the range of nonreciprocal skills, such as following instructions and being able to introduce self and objects. This finding echoed those in the literature that indicate that people with ASD experience the greatest difficulties in maintaining positive relationships with employers and colleagues, which in turn influence the sustainability of the individuals' jobs. In this study, we provided opportunities for participants to proactively demonstrate social skills in real-world settings, such as a teashop where conversations occur naturally.

However, according to the literature, workplace social skills require observation on job sites and follow-up sessions for evaluation. In future studies and practical applications, this intervention package and coaching guidelines may be replicated for a more rigorous design and on-site training after individuals with ASD have obtained a job. In addition, because of the participants' autism characteristics, real-world situations may not always provide the best reinforcement for learned social skills. For example, the withdrawn participant was hesitant to participate and to learn to improve relationships, even with reward systems and activities designed based on his performance, interests, and talent traits. Additional study and practical application are suggested to further investigate strategies to enhance individuals' motivation to learn and to perform necessary workplace social skills. Future studies may include examination of the goodness-of-fit between the results of performance assessments and continuous reinforcement contingencies.

This study had some limitations. The sample population was not randomly selected from the entire rare population of interest; rather, a convenience sample was used. Therefore, the conclusions may not be generalizable to the entire population of young adults with talent traits and ASD. Only one group participated in this experiment study; therefore, the cause-and-effect relationships inferred from the results are tentative.

\section{Acknowledgements}

This work was supported by the Ministry of Science and Technology (MOST 106-2511-S-003-037-MY3).

\section{REFERENCES}

[1] American Psychiatric Association (2013). Diagnostic and Statistical Manual of Mental Disorders-5th Edition. Washington DC: American Psychiatric Association.

[2] Bainbridge, N., \& Smith Myles, B. (1999). The use of priming to introduce toilet training to a child with autism.
Focus on Autism and Other Developmental Disabilities, 14, 106-109.

[3] Barnhill, G. P. (2007). Outcomes in adults with Asperger syndrome. Focus on autism and other developmental disabilities, 22, 116-126.

[4] Burt, D. B., Fuller, S. P., \& Lewis, K. R. (1991). Brief report: Competitive employment of adults with autism. Journal of Autism and Developmental Disorders, 21, 237-242.

[5] Camarena, P. M., \& Sarigiani, P. A. (2009). Postsecondary educational aspirations of high-functioning adolescents with autism spectrum disorders and their parents. Focus on Autism and Other Developmental Disabilities, 24, 115-128.

[6] Cartledge, G., \& Milburn, J. F. (1995). Teaching social skills to children and youth: Innovative approaches. Allyn \& Bacon.

[7] Chan, W., Smith, L. E., Hong, J., Greenberg, J. S., Lounds Taylor, J., \& Mailick, M. R. (in press). Factors associated with sustained community employment among adults with autism and co-occurring intellectual disability. Autism.

[8] Cooper, M. J., Griffith, K. G., \& Filer, J. (1999). School intervention for inclusion of students with and without disabilities. Focus on Autism and Other Developmental Disabilities, 14, 110-115.

[9] Garc, D., Ross, D., \& Wehman, P. (2000). Clinical differential analysis of persons with autism in a work setting: A follow-up study. Journal of Vocational Rehabilitation, 14, 183-185.

[10] García-Villamisar, D., \& Hughes, C. (2007). Supported employment improves cognitive performance in adults with autism. Journal of Intellectual Disability Research, 51, 142-150.

[11] García-Villamisar, D., Wehman, P., \& Navarro, M. D. (2002). Changes in the quality of autistic people's life that work in supported and sheltered employment. A 5- year follow-up study. Journal of Vocational Rehabilitation, 17(4), 309-312.

[12] Gena, A., Couloura, S., \& Kymissis, E. (2005). Modifying the affective behavior of preschoolers with autism using in-vivo or video modeling and reinforcement contingencies. Journal of Autism and Developmental Disorders, 35, $545-556$.

[13] Goldstein, A. P., \& McGinnis, E. (1997). Skillstreaming the adolescent: New strategies and perspectives for teaching prosocial skills. Research Press.

[14] Goldstein, A. P., Sprafkin, R. P., Gershaw, N. J., \& Klein, P. (1980). Skillstreaming the adolescent: A structured learning approach to teaching prosocial skills. Research Press Company.

[15] Haring, T. G., Breen, C. G., Weiner, J., Kennedy, C. H., \& Bednersh, F. (1995). Using videotape modeling to facilitate generalized purchasing skills. Journal of Behavioral Education, 5(1), 29-53.

[16] Harris, L. (1994). NOD/Harris survey of Americans with disabilities. NY: Louis Harris \& Associates.

[17] Hendricks, D. (2010). Employment and adults with autism spectrum disorders: Challenges and strategies for success. 
Journal of Vocational Rehabilitation, 32, 125-134.

[18] Hillier, A., Campbell, H., Mastriani, K., Izzo, M. V., Kool-Tucker, A. K., Cherry, L., \& Beversdorf, D. Q. (2007). Two-year evaluation of a vocational support program for adults on the autism spectrum. Career Development for Exceptional Individuals, 30(1), 35-47.

[19] Hobson, R. P. (1990). On acquiring knowledge about people and the capacity to pretend: Response to Leslie. Psychological Review, 97, 114-121.

[20] Horner, R. H., Carr, E. G., Halle, J., McGee, G., Odom, S., \& Wolery, M. (2005). The use of single-subject research to identify evidence-based practice in special education. Exceptional children, 71, 165-179.

[21] Howlin, P. (2000). Outcome in adult life for more able individuals with autism or Asperger syndrome. Autism, 4, 63-83.

[22] Howlin, P., Alcock, J., \& Burkin, C. (2005). An 8 year follow-up of a specialist supported employment service for high-ability adults with autism or Asperger syndrome. Autism, 9, 533-549.

[23] Howlin, P., Goode, S., Hutton, J., \& Rutter, M. (2004). Adult outcome for children with autism. Journal of Child Psychology and Psychiatry, 45, 212-229.

[24] Hurlbutt, K., \& Chalmers, L. (2002). Adults with autism speak out: Perceptions of their life experiences. Focus on Autism and Other Developmental Disabilities, 17(2), 103-111.

[25] Keel, J. H., Mesibov, G. B., \& Woods, A. V. (1997). TEACCH-supported employment program. Journal of Autism and Developmental Disorders, 27, 3-9.

[26] Lattimore, L. P., Parsons, M. B., \& Reid, D. H. (2002). A prework assessment of task preferences among adults with autism beginning a supported job. Journal of Applied Behavior Analysis, 35(1), 85-88.

[27] Lattimore, L. P., Parsons, M. B., \& Reid, D. H. (2003). Assessing preferred work among adults with autism beginning supported jobs: Identification of constant and alternating task preferences. Behavioral Interventions, 18, 161-177.

[28] Lattimore, L. P., Parsons, M. B., \& Reid, D. H. (2006). Enhancing job-site training of supported workers with autism: a reemphasis on simulation. Journal of Applied Behavior Analysis, 39(1), 91-102.

[29] LeBlanc, L. A., Coates, A. M., Daneshvar, S., Charlop-Christy, M. H., Morris, C., \& Lancaster, B. M. (2003). Using video modeling and reinforcement to teach perspective-taking skills to children with autism. Journal of Applied Behavior Analysis, 36(2), 253-257.

[30] Levy, A., \& Perry, A. (2011). Outcomes in adolescents and adults with autism: A review of the literature. Research in Autism Spectrum Disorders, 5, 1271-1282.

[31] Li, Y. J. (2014). The action study of self-determination employment transition curriculum on vocational high school students with Autism Spectrum Disorder (Unpublished doctoral dissertation). National Taiwan Normal University, Taipei.
[32] Lord, C., Rutter, M., \& Le Couteur, A. (1994). Autism Diagnostic Interview-Revised: a revised version of a diagnostic interview for caregivers of individuals with possible pervasive developmental disorders. Journal of Autism and Developmental Disorders, 24(5), 659-685.

[33] Luecking, R., \& Gramlich, M. (2003). Quality work-based learning and postschool employment success. Issue Brief: Examining Current Challenges in Secondary Education and Transition, 2(2), 1-5.

[34] Mawhood, L., \& Howlin, P. (1999). The outcome of a supported employment scheme for high-functioning adults with autism or Asperger syndrome. Autism, 3, 229- 254.

[35] Mawhood, L., Howlin, P., \& Rutter, M. (2000). Autism and developmental receptive language disorder-A comparative follow-up in early adult life. I: Cognitive and language outcomes. The Journal of Child Psychology and Psychiatry and Allied Disciplines, 41, 547-559.

[36] McConnell, S. R. (2002). Interventions to facilitate social interaction for young children with autism: Review of available research and recommendations for educational intervention and future research. Journal of Autism and Developmental Disorders, 32, 351-372.

[37] Merrell, K. W., \& Gimpel, G. (2014). Social skills of children and adolescents: Conceptualization, assessment, treatment. Psychology Press.

[38] Müller, E., Schuler, A., Burton, B. A., \& Yates, G. B. (2003). Meeting the vocational support needs of individuals with Asperger syndrome and other autism spectrum disabilities. Journal of Vocational Rehabilitation, 18, 163-175.

[39] Nesbitt, S. (2000). Why and why not? Factors influencing employment for individuals with Asperger syndrome. Autism, 4, 357-369.

[40] Njardvik, U., Matson, J. L., \& Cherry, K. E. (1999). A comparison of social skills in adults with autistic disorder, pervasive developmental disorder not otherwise specified, and mental retardation. Journal of Autism and Developmental Disorders, 29, 287-295.

[41] Nuehring, M. L., \& Sitlington, P. L. (2003). Transition as a vehicle: Moving from high school to an adult vocational service provider. Journal of Disability Policy Studies, 14(1), 23-35.

[42] Persson, B. (2000). Brief report: A longitudinal study of quality of life and independence among adult men with autism. Journal of Autism and Developmental Disorders, 30, 61-66.

[43] Presidential Order (2009). The Special Education Act. Hua-Zong-Yi-Yi-Zi 09800289381 amended November 18, 2009.

[44] Rotheram-Fuller, E., Kim, M., Seiple, D., Locke, J., Greenwell, R., \& Levin, D. (2013). Social skills assessments for children with autism spectrum disorders. Autism, 3, 2.

[45] Schreibman, L., Whalen, C., \& Stahmer, A. C. (2000). The use of video priming to reduce disruptive transition behavior in children with autism. Journal of Positive Behavior Interventions, 2(1), 3-11.

[46] Sigafoos, J., O’Reilly, M., Cannella, H., Upadhyaya, M., 
Edrisinha, C., Lancioni, G. E., \& Young, D. (2005). Computer-presented video prompting for teaching microwave oven use to three adults with developmental disabilities. Journal of Behavioral Education, 14, 189-201.

[47] Simpson, A., Langone, J., \& Ayres, K. M. (2004). Embedded video and computer based instruction to improve social skills for students with autism. Education and Training in Developmental Disabilities, 39, 240-252.

[48] Smith, M. D. (1995). A Guide to Successful Employment for Individuals with Autism. Paul H. Brookes Publishing Co., Baltimore.

[49] Wang, H. T., \& Koyama, T. (2014). An analysis and review of the literature and a three-tier video modeling intervention model. Research in Autism Spectrum Disorders, 8, 746-758.

[50] Weiss, M. J., \& Harris, S. L. (2001). Teaching social skills to people with autism. Behavior Modification, 25, 785-802.

[51] Weng, S. Z., Liao, F. M., \& Li, Y. J. (2011). Social Skill Course Design of Resource Class in Junior High School. Ministry of Education, Taipei. (In Chinese).

[52] Weng, S. Z., Zhao, S. L., Li, Y. J., Zhu, Y. A., \& Chang, S. Y. (2015). Workplace Social Skill Course in Vocational High School. Department of Education, Taipei City Government, Taipei. (In Chinese).

[53] Wong, C., Odom, S. L., Hume, K. A., Cox, A. W., Fettig, A., Kucharczyk, S., ...Schultz, T. R. (2015). Evidence-based practices for children, youth, and young adults with autism spectrum disorder: A comprehensive review. Journal of Autism and Developmental Disorders, 45, 1951-1966. 